\title{
Renewable energies evaluation and linking to smart grid
}

\author{
Benouaz Idriss Yassine ${ }^{1}$, Allaoua Boumediene ${ }^{2}$ \\ ${ }^{1}$ Laboratory of Analysis, Control and Optimization of Electro-Energetic Systems, Tahri Mohammed University, Algeria \\ ${ }^{2}$ Smart Grids and renewable energies Laboratory, Tahri Mohammed University, Algeria.
}

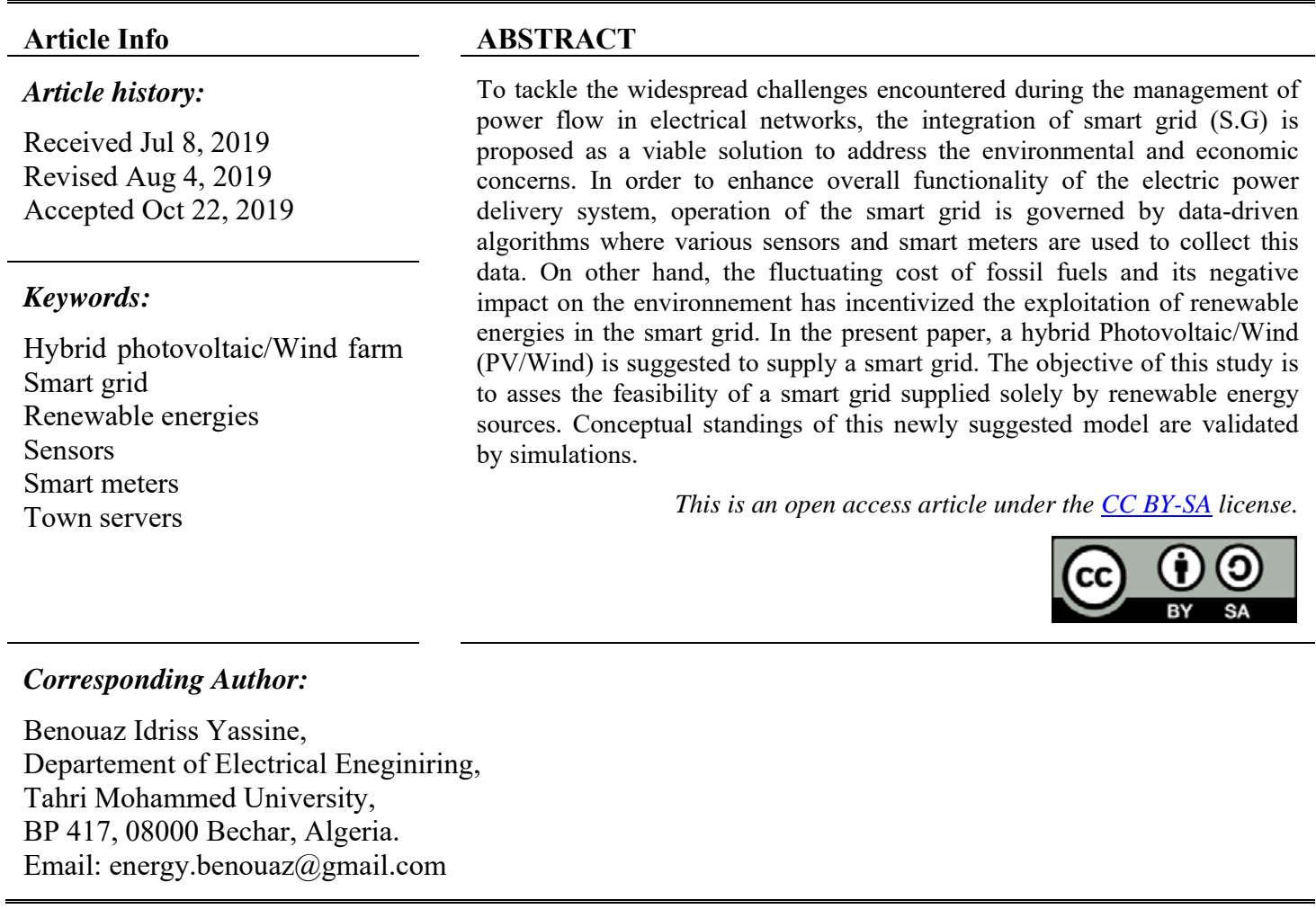

\section{INTRODUCTION}

The term "smart grid" defines a self-healing network using sensors, two-ways communications, computational ability, control and dynamic optimization techniques that use real-time measurements to minimize network losses, maintain voltage levels, increase reliability and improve asset management [1]. Furthermore, the worldwide energy infrastructure depends heavily on burning fossil fuels. Given that those resources are non-renewable and are considered to be the main source of pollution, extensive research is conducted to look for new clean sources of energy and to improve the already existing renewable energy sources (RESs) [2]. In comparison with the remaining RESs, the Wind and PV sources are implemented frequently as an auxiliary system to the main conventional production resources [3]. Furthermore, the excess of energy harvested from the RESs is stored for use in case of load shedding to guarantee the continuity of service [4].

The continuous growth of residential and industrial and consumers increases the burdens on the traditional electrical power grid and creates new issues like continuous blackouts and increasing carbon emissions [5]. Two-way communication strategy along with use of sensors and smart meters in the S.G is apoted for to solve these issues and to add intelligence and automation to the way operations are carried out in S.G. The main interest in this paper is to asses the use hybrid PV/Wind farm as a sole supply of a smart grid, different power demand cases are considered to simulate for a real behaviour of an electrical network. 


\section{HYBRID RENEWABLE ENERGY PV/WIND}

\subsection{Solar energy}

The solar energy is harvested using Concentrated Solar Panels (CSP) or Photovoltaic (PV) panels. Using the PV panels the solar radiation is converted to electric energy [6, 7]. In order to tie an array of solar panels to the utility grid with the required frequency and voltage level, the produced energy from the PV panels is converted from direct current (DC) to alternatif current (AC) form using an inverter. The entire system is illustrated in Figure 1 [8].

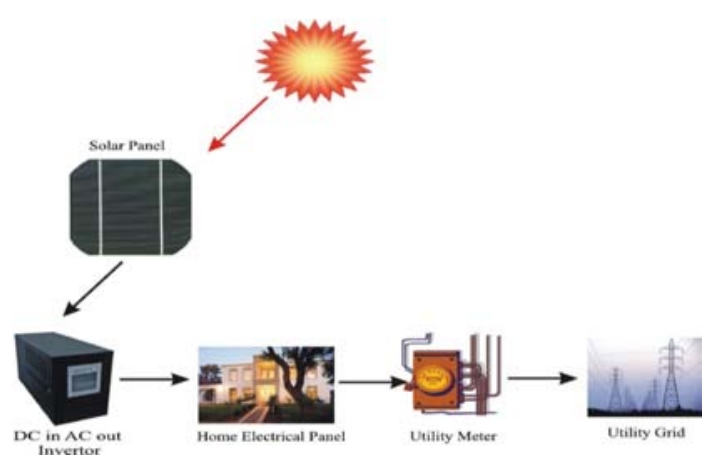

Figure 1. Grid connection to photovoltaic system

\subsection{Wind energy}

Thanks to the extensive research conducted on the wind energy system, energy conversion efficiency has raised significantly and therefore several wind farms has been implemented and tied to the networks where wind potential is high. The abudance of wind in some locations has helped to provide almost continuous source of electricity. While wind farms do not need batteries for backup storage of electricity, small wind systems does need backup batteries [9]. Kinetic Energy (KE) of the wind is converted into mechanical energy by means of blades of the wind turbine, then a generator is connected to the wind turbine to converts mechanical energy to electrical energy [10] as shown in Figure 2.

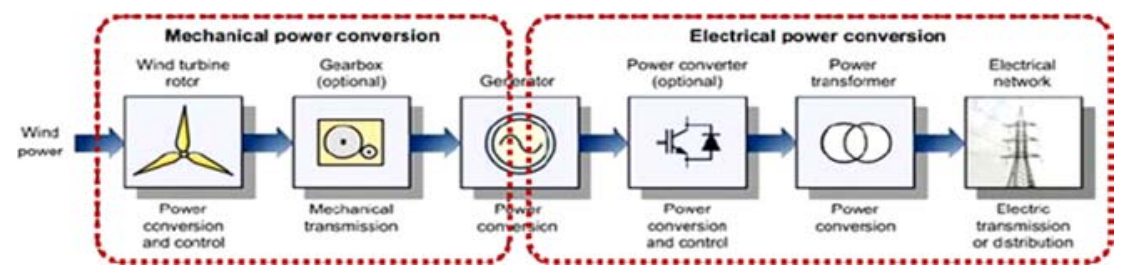

Figure 2. Wind power conversion to electricity in a wind turbine

\section{HYBRID SYSTEM MODELING}

3.1. Photovoltaic generator model

Given that the performance of photovoltaic systems is affected by irradiance levels and temperature, many simplified simulation models has been conceived to improve the performance PV systems. An example of the solar cell circuit model is shown in Figure 3.

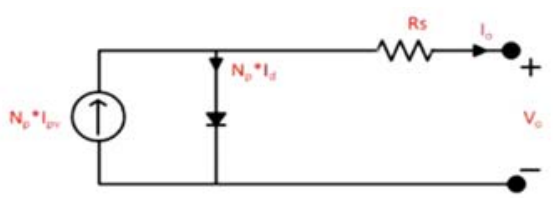

Figure 3. Solar cell with single-diode and series resistance 
This photovoltaic panel can be modeled using the following equations:

$$
\begin{aligned}
& I_{r r}=I_{s c r} /\left[e^{\left.\left(q * V_{o C} / K * N_{S} * A * T_{r K}\right)-1\right]}\right. \\
& I_{d}=I_{r r} *\left(T_{a K} / T_{r K}\right)^{3} * e\left[\left(E_{g} * q / K * A\right) *\left\{1 / T_{r K}-1 / T_{a K}\right\}\right] \\
& I_{p v}=\left[I_{S c r}+\left(K_{i} *\left(T_{a K}-T_{r K}\right)\right)\right] * S / 100 \\
& I_{0}=N_{p} * I_{p v}-N_{p} * I_{d} *\left\{e\left[\left(q / N_{S} * A * K * T_{a K}\right) *\left(V_{0}+I_{0} * R_{S}\right)\right]-1\right\}
\end{aligned}
$$

\subsection{Wind turbine model}

The wind turbine systems are also affected by the weather. Wind turbines are usually connected in parallel. An equivalent circuit of wind turbine is represented as shown in Figure 4 [11].

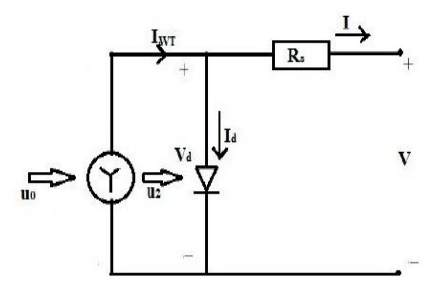

Figure 4. Equivalent circuit of wind turbine

This wind turbine panel can be modeled using the following equations:

$$
\begin{aligned}
& P_{0}=1 / 2[\rho A u 0]^{3} \\
& P_{w}=1 / 2[m(u 0-u 2)] \\
& P(t)=\eta w^{*} \eta g^{*} 0.5 * \rho a * C P * A * V r 2
\end{aligned}
$$

\section{SMART GRID DESCRIPTION}

The smart system is a combination of four main parts: Smart House System (S.H), Smart Meter (S.M), Town Server (T.S) and Main Server (M.S). The collaborative and proper operation of these systems will help optimize the consumption of energy and mitigate the pollution.

\subsection{Smart house system}

A smart home is an application of ubiquitous computing in which the home environment is monitored by ambient intelligence to provide context-aware services and facilitate remote home control [12]. It is equipped with all smart appliances. The installation of the smart cards is needed to make the devices smart. These cards are consisting of wireless cards, sensors, micro controllers and digital meters. Using these smart appliances, the communication between the devices and the S.M will no longer need a smart socket $[13,14]$. The power consumption is sensed by the sensor device, it also decide the status of current. The consumed power and its price are shown by a digital meter. The power flow is controlled by the micro controller device. The power required for appliance is also known to the micro controller, this information will be send to a S.M through a wireless card. Smart card and smart meter are connected with wireless card by wireless communication [15].

\subsection{Smart Meter}

The basic purposes of S.M systems are [16]: 


\subsubsection{Power management and measuring}

The input from the smart grid/power station is taken by the S.M that has information of total power amount required by the smart application [17]. If the provided power from the smart grid/power station is insufficient it will try to fulfil requirement by extracting power from regenerative source (R.S), and if R.Ss are not able to satisfy power requirement then the T.S will receive a signal from S.M to provide difference of required power and available power. If the power required is less than the power provided by T.S, it broad cast a message to T.S that T.S provided power is more than require so T.S can reduce power which is more than require power by $\mathrm{S}$. H [18].

\subsubsection{Unit measurement and price}

The power consumption unit is measured by the S.M, this operation will be done in three levels

- $\quad$ Power units provided by service provider to estimate the price.

- $\quad$ Power units extracted from R.S.

- $\quad$ The utilization of the power units extracted from R.S by service provider to run another S.H.

S.M will calculate the price up to time using above mentioned readings. It will be visible to customer [19].

\subsubsection{Communication}

In order to send and receive the message signal, T.S has to communicate with S.M. This is done using Public switched telephone network (PSTN). PSTN technology usages remove the high power radiation present in S.M communication [20, 21]. T.S will receive the price and units number from the S.M so the customer can finally pay the service provider. All T.Ss are connected to a M.S using PSTN. While for power transmission, S.M is also connected to T.S via power line.

\subsection{Town server}

In a smart grid the town server is the basic unit of management, it is a complete server which is able to take decision for its users. The T.S has to be connected to an M.S to send the calculated power units up to that time each hour, which means that all data will be saved at the M.S while T.S keeps only the current month data for efficient working. The mean purpose of sending data each hour is to remove the possibility of over burdening of bandwidth and also to reduce the bandwidth to considerably low level than previous smart system. In case that the M.S goes to link down state, T.S switch automatically to administrative mode and behaves like main server for itself and keeps data until M.S again goes to linkup state, which is why the T.S is operated by multitasking real time operating system and real time software. In the smart system T.Ss are connected to each other via PSTN's and via power lines it can be seen in Figure 6 . These both links are important for the management between T.Ss. The draw backs of previous system and latest needs are the one strongest reason which appeals to use PSTN is theoretically unlimited bandwidth availability [18]. Shannon theorem gives bandwidth equation as given below [22]:

$$
b_{p s}=B W \log 2(I+P I N)
$$

And bit per second is given by equation:

$$
b_{p s}=R_{S} \log 2 N_{S}
$$

Initially, the S.M send a message containing the amount of power needed by its S.H, these messages will be received by T.S from all of its S.Ms, so T.S will be informed when the power required for an S.H decrease or increase instantly. Whenever an S.M send a message to T.S to reduce its power and other one to increase its, T.S will reduce the power suggested from the first one and sends it to the second depending on its requirement. In case that the power suggested from the first one is insufficient for the requirement of second, T.S will check other S.Hs those can provide power to compensate power deficiency. When there are no S.Hs can provide power or the power regenerated is less then it broadcast a message signal to its nearest T.S to provide power it can be seen in Figure 5. If the nearest town server can donate power from its grids it will borrow from next T.S for the first one. If there is problem at M.S or any / few T.Ss, the other T.Ss will work properly it can be seen in Figure 6.

This is an advantage of smart system over any other systems. T.S may or may not be connected directly to smart grid or conventional power station or both, this connection is done as simple as connecting a main central computer of smart grid to the smart grid.

Int J Pow Elec \& Dri Syst Vol. 11, No. 1, Mar 2020 : $107-118$ 


\subsection{Main server}

From the previous sections it can be easily seen that the M.S is the brain of the smart grid system. It keep costumer records, bills, topology of division of all the power of smart grids/power stations for relevant smart towns, etc. As mentioned before, M.S is connected to all T.Ss via PSTN it can be seen in Figure 6. M.S can start or stop all the functionality of a particular T.S/S.H in any severe case by some type of commands and passwords even if it is operated by deferent head offices of service provider working under single umbrella. At the end of the month a complete summary is generated and recorded by the M.S for each T.S and each S.H. It informs the customer about all their power consumption and their bills using their selected media (email, sms, by post, etc.) [16].

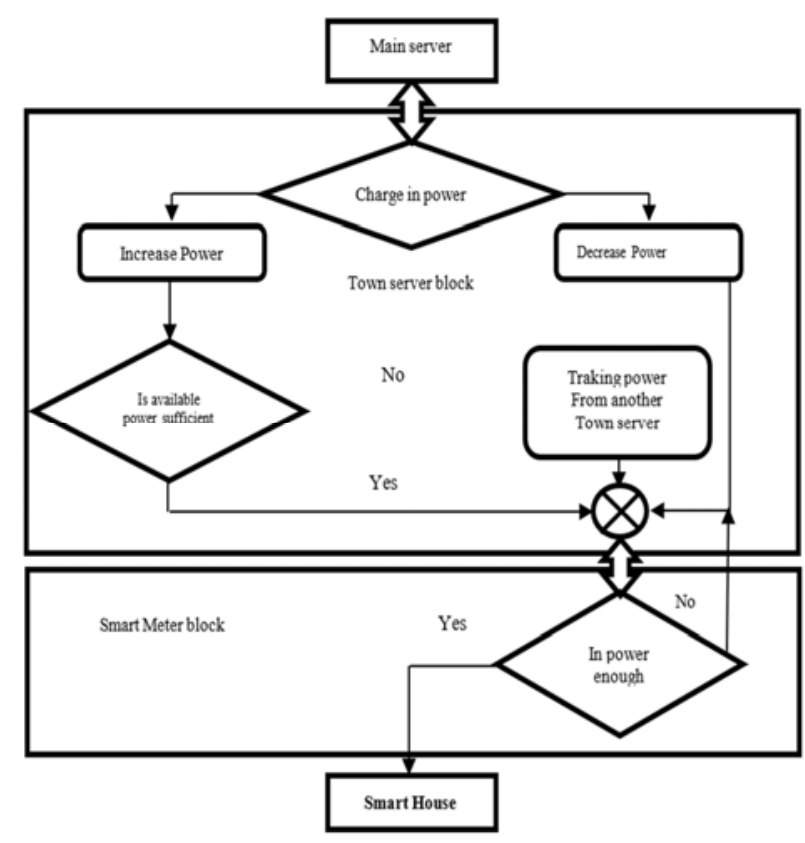

Figure 5. Flow chart of smart system

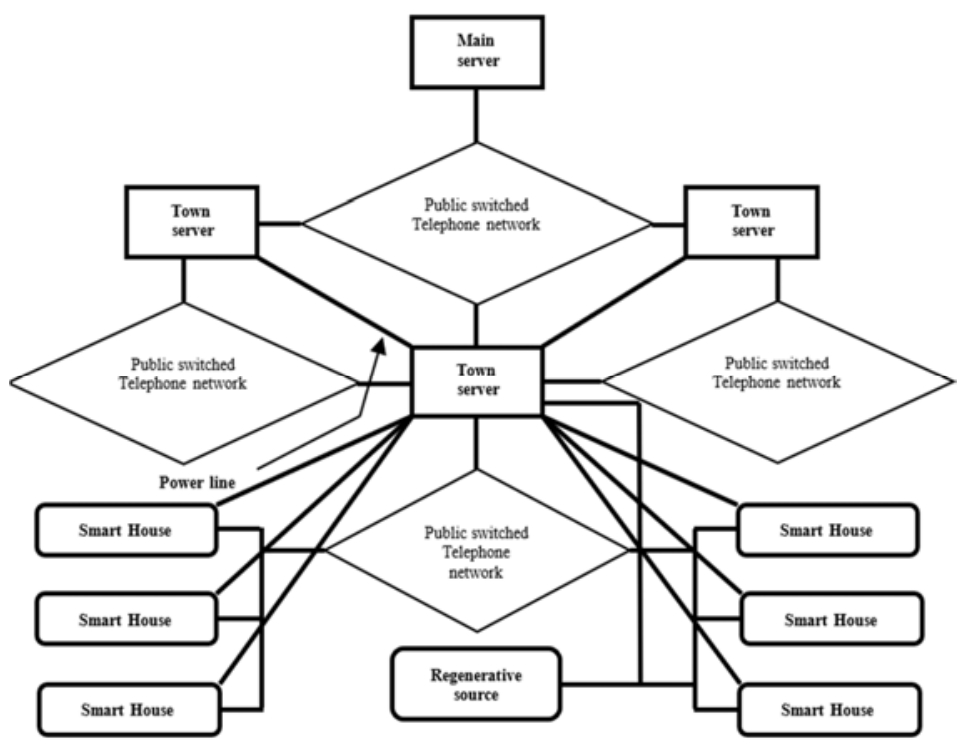

Figure 6. Topology of smart system; upper part shows way of connection between TS and also with MS while lower part shows the way of connection of SH to TS through local PNST. 


\section{SIMULATION RESULTS AND DISCUSSION}

In this paper, a hybrid PV/Wind farm is exploited to supply a smart grid system. In addition, batteries are used to stock the excess of energy. The block diagram of the proposed system is shown in Figure 7.

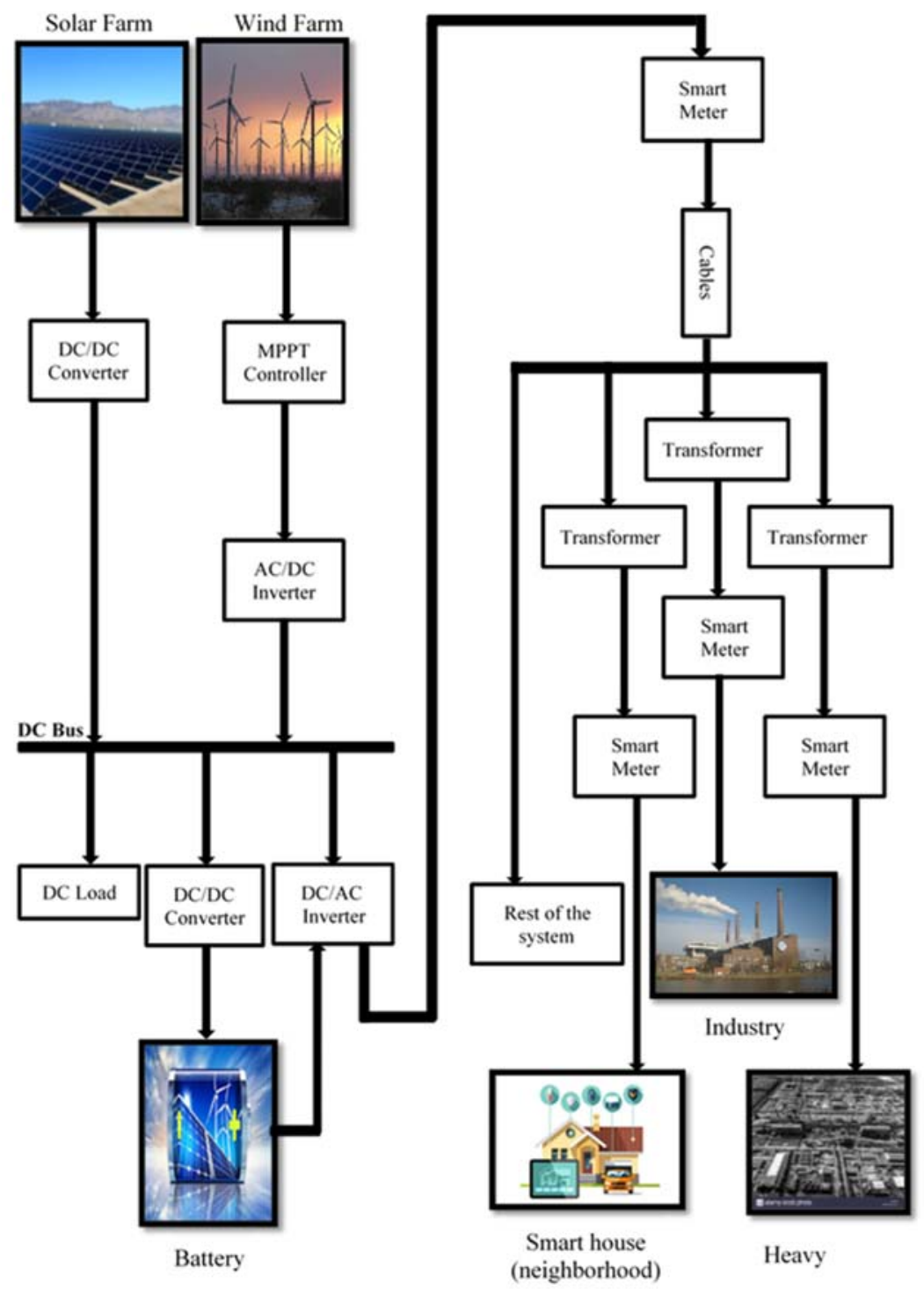

Figure 7. Block diagram of the proposed system.

\subsection{The hybrid $P V / W i n d$ farm proposed to supply our smart grid}

\subsubsection{PV farm}

As illustrated in Figure 8, it can be seen that:

- From $\mathrm{t}=0 \mathrm{~s}$ to $\mathrm{t}=2 \mathrm{~s}$, knowing that the radiation was $1000 \mathrm{~W} / \mathrm{m} 2$, the PV voltage is increasing to reach 29 $\mathrm{kV}$, the courant is almost constant in $300 \mathrm{~A}$ and the power is increasing until $8.5 \mathrm{MW}$.

- From $t=2 s$ to $t=4 \mathrm{~s}$, the weather has changed and the radiation has decreased to $850 \mathrm{~W} / \mathrm{m} 2$, the PV voltage is still increasing to reach $32 \mathrm{kV}$ but the courant has decreased to $246 \mathrm{~A}$ and became constant. The power has decreased in the beginning to $7 \mathrm{MW}$ and increase again to reach 7.9 MW.

- $\quad$ From $\mathrm{t}=4 \mathrm{~s}$ to $\mathrm{t}=6 \mathrm{~s}$, the radiation has gone (at night) so the PV farm has stopped the power generation. 


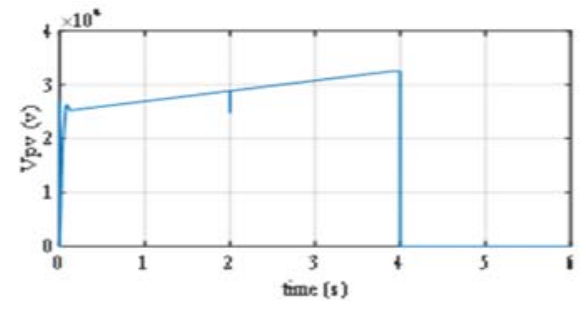

(a)

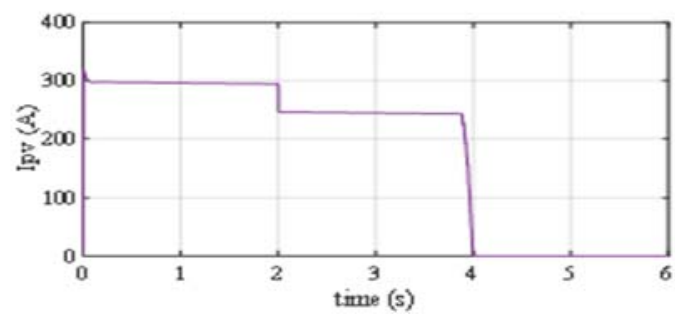

(b)

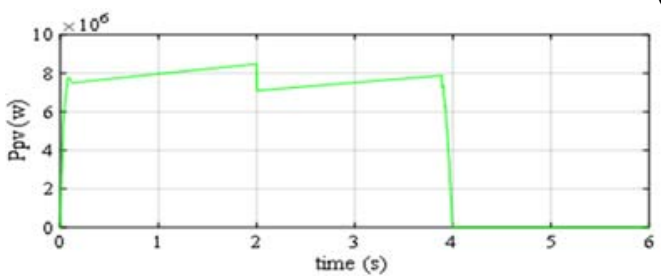

(c)

Figure 8. The photovoltaic farm simulation results: (a) Voltage produced, (b) Current produced, (c) Power produced

\subsubsection{Wind farm}

As shown in Figure 9, it can be observed that:

- From $\mathrm{t}=0 \mathrm{~s}$ to $\mathrm{t}=0.5 \mathrm{~s}$, knowing that the wind speed was $5 \mathrm{~m} / \mathrm{s}$ the wind voltage has increase to $100 \mathrm{~V}$ in beginning and decrease after that until $10 \mathrm{~V}$, the courant has reach $6 \mathrm{~A}$ and go back to almost $0 \mathrm{~A}$. The power increase to $1100 \mathrm{~W}$ and go back to $0 \mathrm{~W}$.

- From $\mathrm{t}=0.5 \mathrm{~s}$ to $\mathrm{t}=3 \mathrm{~s}$, the weather has changed and the wind speed has increased to $12 \mathrm{~m} / \mathrm{s}$, the wind voltage keeps changing starting from $10 \mathrm{~V}$ increasing to $105 \mathrm{~V}$ from $\mathrm{t}=0.9 \mathrm{~s}$ to $\mathrm{t}=1.6 \mathrm{~s}$ decreasing to $0 \mathrm{~V}$ at $\mathrm{t}=2 \mathrm{~s}$ and increasing again to $100 \mathrm{~V}$ from $\mathrm{t}=2.5 \mathrm{~s}$ to $\mathrm{t}=3 \mathrm{~s}$, the same think for the courant starting from 0 $\mathrm{A}$ at $\mathrm{t}=0.5 \mathrm{~s}$ increasing to $38 \mathrm{~A}$ at $\mathrm{t}=1.4 \mathrm{~s}$, decreasing to $0 \mathrm{~A}$ at $\mathrm{t}=2 \mathrm{~s}$ and increase again to reach $35 \mathrm{~A}$ at $\mathrm{t}=3 \mathrm{~s}$. The power has increased to $6300 \mathrm{~W}$ at $\mathrm{t}=1.5 \mathrm{~s}$, decreased to $0 \mathrm{~W}$ at $\mathrm{t}=2 \mathrm{~s}$ and increased again to reach 5800 at $\mathrm{t}=3 \mathrm{~s}$.

- From $t=3 \mathrm{~s}$ to $\mathrm{t}=6 \mathrm{~s}$, the weather has changed again and the wind speed has decreased to $9 \mathrm{~m} / \mathrm{s}$, the wind voltage has been increasing until reaching $1600 \mathrm{~V}$ at $\mathrm{t}=6 \mathrm{~s}$, the courant keeps changing from $0 \mathrm{~A}$ to $23 \mathrm{~A}$ and the power keeps changing from $0 \mathrm{~W}$ to $45 \mathrm{~kW}$.

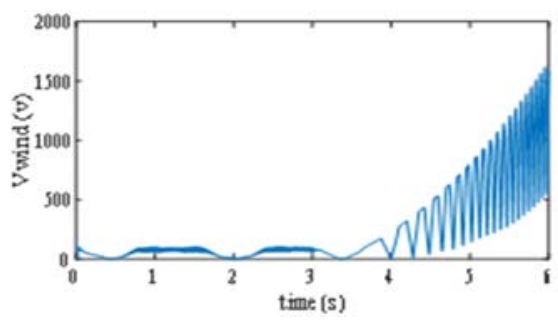

(a)

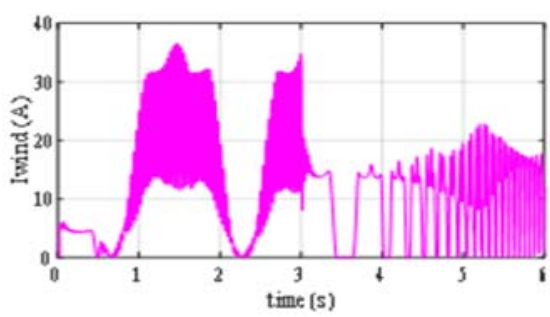

(b)

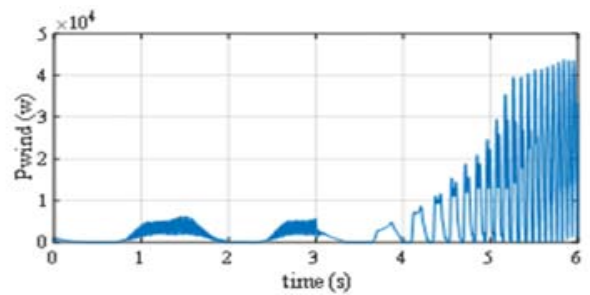

(c)

Figure 9. The wind farm simulation results: (a) Voltage produced, (b) Current produced, (c) Power produced 


\subsubsection{Load energy demand}

The load charge demand was $9.1 \mathrm{MW}$ until $\mathrm{t}=4 \mathrm{~s}$, it was increased to reach $1.26 \mathrm{MW}$ from $\mathrm{t}=4 \mathrm{~s}$ to $\mathrm{t}=5 \mathrm{~s}$ and go back again to $9.1 \mathrm{MW}$ from $\mathrm{t}=5 \mathrm{~s}$ to $\mathrm{t}=6 \mathrm{~s}$. The detail ish shown in Figure 10 .

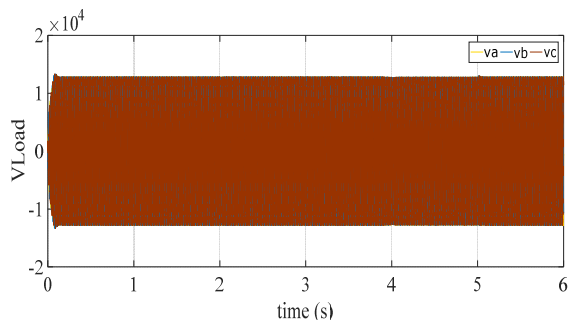

(a)

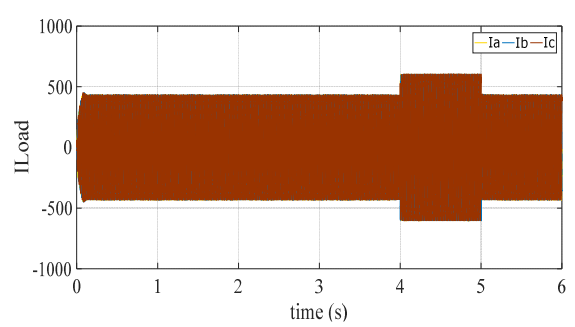

(c)

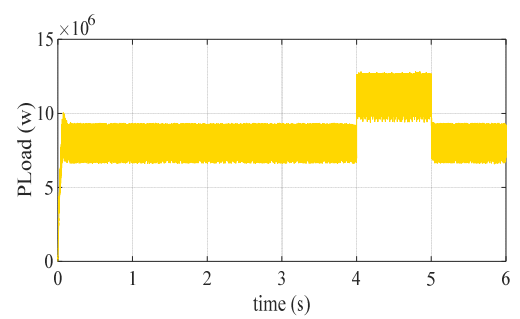

(e)

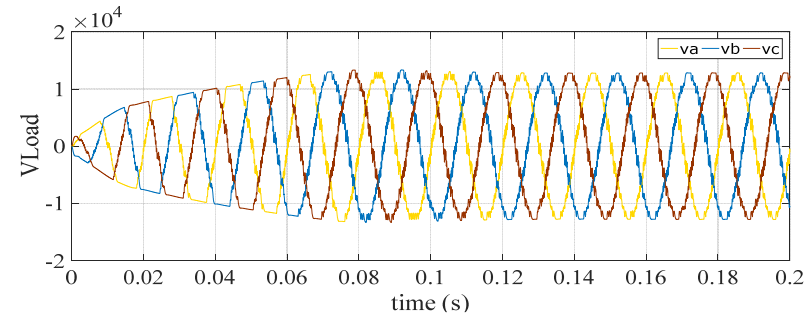

(b)

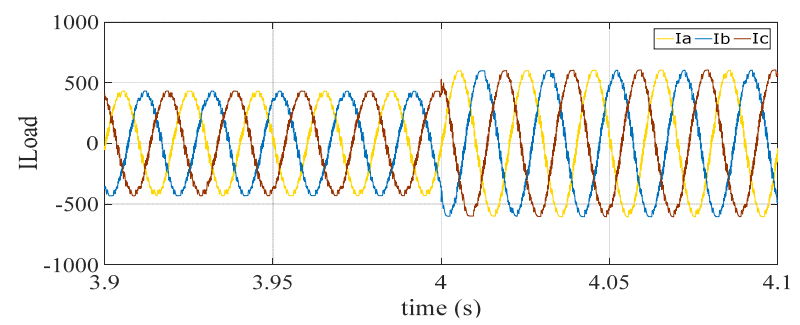

(d)

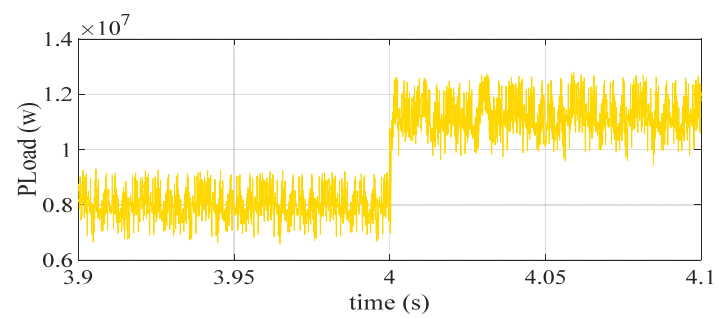

(f)

Figure 10. The load demand simulation results: (a) Voltage demand, (b) Zoom of voltage demand from 0s to 0.2s, (c) Current demand, (d) Zoom of current demand from 3.9s to 4.1s, (e) Power demand, (f) Zoom of power demand from

$$
3.9 \mathrm{~s} \text { to } 4.1 \mathrm{~s} \text {. }
$$

\subsubsection{Comparing results}

As shown in Figure 11 the PV farm and the wind farm are working together as hybrid PV/Wind energy source to fulfil the load demand, the results show that:

- From $t=0 s$ to $t=4 s$, even when the PV farm power had decreased at $t=2 s$ the wind farm power had increased to compensate the lack of power.

- $\quad$ From $t=4 \mathrm{~s}$ to $\mathrm{t}=5 \mathrm{~s}$ the charge demand had increased and the PV farm power had decreased so the wind farm power had increased to supply the charge demand by itself.

- From $t=5 \mathrm{~s}$ to $\mathrm{t}=6 \mathrm{~s}$, the charge demand had gone back to normal but the PV farm had no power to generate so the wind farm power had continue to supply the demand by itself.

To supply this load the following equation had to be checked:

$$
P_{\text {load }}=P_{p v} \pm P_{\text {wind }} \pm P_{\text {batteries }}
$$




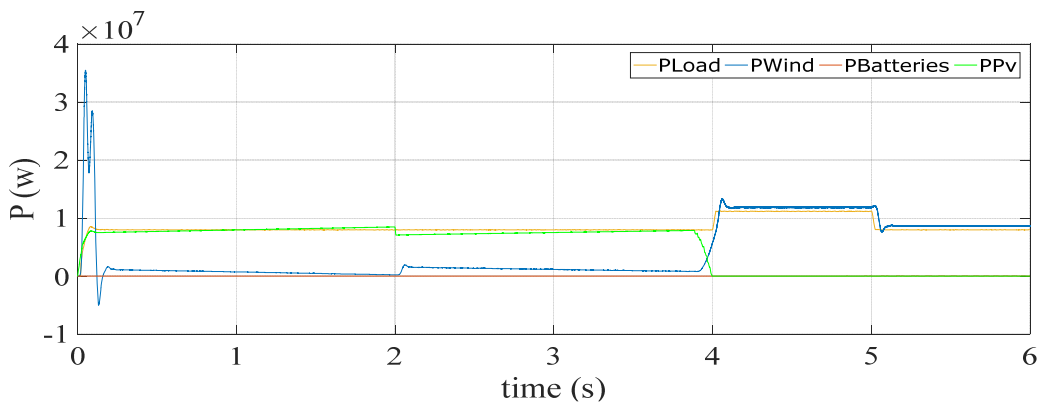

Figure 11. The comparison results of hybrid PV/Wind farm and power demand

\subsection{The smart grid proposed}

The smart grid proposed consists of five smart houses (neighbourhood), four industries, one heavy industry and the rest of the system.

\subsubsection{Smart houses}

House five is taken as an example to discuss the results. This house is supplied by the grid power, wind generator with a capacity of $1 \mathrm{KW}$ and solar panels with a capacity of $4,5 \mathrm{KW}$. The results are shown in Figure 12.

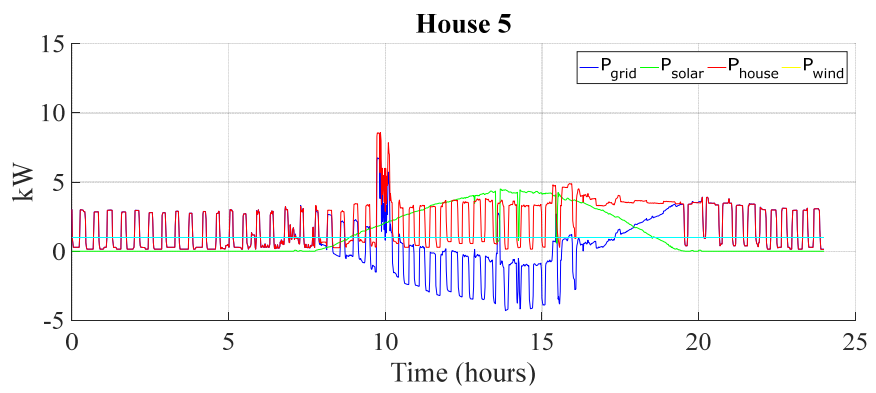

Figure 12. Smart house simulation results

After following the program for twenty-four hours, it can be seen that:

- From 00:00 to 08:00, the house power consumption is supplied by both of grid power and wind generator.

- $\quad$ From 8:00 to 09:40, following the appearance of the day the solar power intervenes so it can supply the house power demand with the wind power, in this period the grid was discharged from supplying the house so the consumer can sell or store the excess power.

- From 09:40 to 10:00, a peak of power consumption was observed, the solar power and the wind power cannot supply it by them self so the grid power intervene to fulfill the lack of power.

- From 10:00 to 18:00, the power consumption of the house was supplied by the solar and the wind energy except at 13:30 and 15:30 where we can see that the power consumption was increased so the grid power had intervened to supply it.

- $\quad$ From 18:00 to the end of the day, the solar energy had decreased (sun down) so the grid power and the wind power had insured the power for this house.

\subsubsection{Industries}

To discuss the result, industry two was taken as an example. This industry is supplied by the grid power, wind generator with a capacity of $1 \mathrm{KW}$ and solar panels with a capacity of $4,5 \mathrm{KW}$. The results are shown in Figure13. 


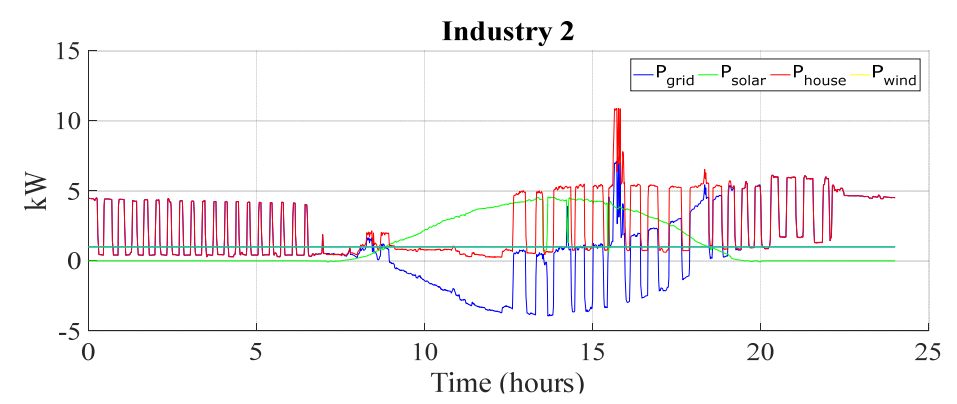

Figure 13. Industry simulation results

After following the program for twenty-four hours, it can be observe that:

- From 00:00 to 08:48, the industry consumption is supplied by both of grid power and wind generator.

- From 08:48 to 12:36, following the appearance of the day the solar power intervenes so it can supply the industry power demand with the wind power, in this period the grid was discharged from supplying the industry.

- $\quad$ From 12:36 to $15: 36$, the industry power consumption increasing and decreasing, in this period the grid power intervenes only when the power consumption increase.

- From 15:36 to 16:00, a big peak of $11 \mathrm{KW}$ has been observed, in this case the grid power intervenes immediately to fulfil the lack of power.

- From 16:00 to 18:30, the solar power decrease gradually (sun down) so the grid power increase gradually to fulfill the lack of power, in this period the industry power demand is supplied by the grid, wind and solar powers.

- From 18:30 to 20:18, the power consumption of the industry has been supplied by the grid and wind powers.

- $\quad$ From 20:18 to the end of the day, the industry power increased, in this period the grid power supply it by it self.

\subsubsection{Heavy industry:}

The heavy industry is supplied by the grid power, wind farm with a capacity of $1 \mathrm{MW}$ and solar farm with a capacity of 8MW. The results are shown in Figure 14.

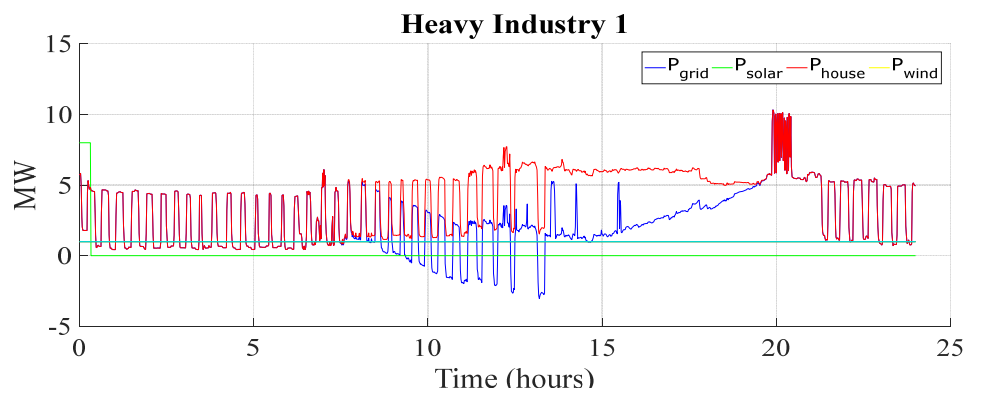

Figure 14. heavy industry simulation results

After twenty-four hours of observation, the results had shown that:

- From 00:00 to 13:15, a few minutes in the beginning the power stocked by the solar had helped the grid to supply the heavy industry then the grid power and the wind power take the task. We can see in this period that when the heavy industry demand decreases the wind power supply it by itself.

- From 13:15 to 23:00, the power demand of the heavy industry increases and only the grid power can supply it.

From 23:00 to the end of the day, the supply demand decreases and it can be supplied by the grid and wind powers

Int J Pow Elec \& Dri Syst Vol. 11, No. 1, Mar 2020 : $107-118$ 


\section{CONCLUSION}

The main objective of this study is to asses the operation of a hybrid PV/Wind farm supplying a smart grid. The sub-systems involved in the smart grid has been modeled. For a comprehensive assesement of the entire system, each subsystem has been simulated under different operating scenarios. Results has shown that the conceived system composed of solely renewable energies and a smart grid can provide secure and efficient power source, especially when these PV/Wind system are installed in locations with abudance of wind and with excellent irradiation levels.

\section{ACKNOWLEDGEMENTS}

Authors would like to thank the heads of Laboratory of Analysis, Control and Optimization of Electro-Energetic Systems (CAOSEE) and Smart Grids and renewable energies (ENERGARID) at the university TAHRI Mohammed of Bechar (Algeria).

\section{Nomenclatures:}

I0 Is the output current of the PV module

$V_{0} \quad$ Is the output voltage of the PV module

$T_{r K} \quad$ Is the reference temperature in kelvin

$T_{a K} \quad$ Is the module operating temperature in kelvin

$\mathrm{S} \quad$ Is the PV module operating temperature in kelvin

q Is electron charge $1.6^{*} 10^{\wedge}-19 \mathrm{C}$

$\mathrm{A}=\quad 1.3$ is an ideality factor

$\mathrm{K} \quad$ Is Boltzman constant $1.3805 \mathrm{e}-23 \mathrm{j} / \mathrm{K}$

Eg Os the band gap of Si $1.12 \mathrm{eV}$

I scr Is the PV short circuit current at $25 \mathrm{C} \mathrm{\&} \mathrm{S=1000} \mathrm{W/} \mathrm{cm}^{2}$

$N_{S} \quad$ Is the number of cells connected in series

$N_{p} \quad$ Is the number of cells connected in parallel

$K_{i} \quad$ Is the short circuit temperature coefficient at $I_{s c r} 0.0013 \mathrm{~A} /{ }^{\circ} \mathrm{C}$

$R_{S} \quad$ Is the series resistance of PV module

I pv Is the light generated current of the PV module

Id Is the PV module saturation current

$P W \quad$ Output power in watts

$P_{a} \quad$ Extracted output from wind in watts

$P_{w t} \quad$ Generated output power in watts

$\eta w \quad$ Wind turbine efficiency

$\eta g \quad$ Generator efficiency

$\mathrm{a} \quad$ Air density

$\mathrm{CP} \quad$ Power co-efficient of wind turbine

A Wind turbine swept area

bps $\quad$ Bits per second

BW Channel bandwidth

$P / N \quad$ Signal to noise power ratio. This is a real power ratio and not a $\mathrm{dB}$ ratio.

$R_{S} \quad$ symbol rate (also bandwidth for QAM)

$N_{S} \quad$ number of symbols in the constellation

\section{REFERENCES}

[1] James Momoh, "Smart Grid: Fundamentals of Design and Analysis," Hoboken: New Jersey, 2012.

[2] Jaradat M, Jarrah M, Jararweh Y, Al-Ayyoub M, Bousselham A, "Integration of Renewable Energy in DemandSide Management for Home appliances," International Renewable and Sustainable Energy Conference (IRSEC), Ouarzazate, pp. 571-576, 2014

[3] Vinu Thomas, Sivaprasad Athikkal, Kumaravel Sundaramoorthy, Ashok Sankar, "Testing of a Solar-PV/Wind Operated AC-DC Microgrid with LabVIEW Controller," International Journal of Power Electronics and Drive System (IJPEDS), vol. 9, no. 1, pp. 406-413, 2018. 
[4] R. Bayindir, I. Colak, G. Fulli, K. Demirtas, "Smart grid technologies and applications," Renewable and Sustainable Energy Reviews, vol. 66, pp. 499-516, 2016.

[5] X. Fang, S. Misra, G. Xue, and D. Yang, "Smart grid; the new and improved power grid: A survey," Communications Surveys Tutorials IEEE, vol. 14, No. 4, pp. 944-980, 2012.

[6] Abdelkader Mezouari, R. Elgouri, M. Alareqi, K. Mateur, H. Dahou, L. Hlou, "A New Photovoltaic Blocks Mutualization System for Micro-Grids Using an Arduino Board and Labview," International Journal of Power Electronics and Drive System (IJPDES), vol. 9, no. 1, pp. 98-104, 2018.

[7] Taoufik Laagoubi, Mostafa Bouzi, Mohamed Benchagra, "MPPT \& Power Factor Control for Grid Connected PV Systems with Fuzzy Logic Controllers," International Journal of Power Electronics and Drive System (IJPEDS), vol. 9, No. 1, pp. 105-113, 2018.

[8] N.L. Panwar, S.C. Kaushik, Surendra Kothari, K., "Role of renewable energy sources in environmental protection: A review," Renewable and Sustainable Energy Reviews, vol. 15, pp. 1513-1524, 2011.

[9] Ayhan Demirbaş, "Global Renewable Energy Resources," Energy Sources, Part A: Recovery, Utilization, and Environmental Effects, vol. 28, no. 8, pp. 779-792, 2006.

[10] Sujit Kumar Bhuyan, Prakash Kumar Hota, Bhagabat Panda, "Power Quality Analysis of a Grid-Connected Solar/Wind/Hydrogen Energy Hybrid Generation System," International Journal of Power Electronics and Drive System (IJPEDS), vol. 9, no. 1, pp. 377-389, 2018.

[11] Balamurugan.T, Manoharan. S., "Optimal Power Flow Management Control for Grid Connected Photovoltaic/Wind turbine/Diesel generator (GCPWD) Hybrid System with Batteries," International Journal of Renewable Energy Research, vol. 3, no. 4, pp. 819-826, 2013.

[12] Alam M. R, Reaz M. B. I, Ali, M. A. M., "A review of smart homes-past, present, and future," IEEE Transactions on Systems, Man, and Cybernetics, Part C (Applications and Reviews), vol. 42, no. 6, pp. 1190-1203, 2012.

[13] Moslehi. K, Kumar R., "A Reliability Perspective of the Smart Grid," IEEE Transactions on, Smart Grid, vol. 1, no. 1, pp. 57-64, 2010.

[14] Rozeha A Rashid, Mohd Adib Sarijari, Mohd Rozaini Abd Rahim, Tan Zun Yung, "Flood Transmission based Protocol for Home Automation System via Power Line Communication," Proceedings of the International Conference on Computer and Communication Engineering, 2008.

[15] Ali Mekkaoui, Mohammed Laouer, Younes Mimoun, "Modeling and simulation for smart grid integration of solar/wind energy," Leonardo Journal of Sciences, issue. 30, pp. 31-46, 2017.

[16] Rao M. Navid-Ur-Rehman, Zubair Ahmed, Adnan Faroqi, "Model of Smart System Based On Smart Grid, Smart Meter and Wireless Based Smart Appliances," Journal of Electrical and Electronics Engineering, vol. 1, no. 5, pp. 6-10, 2012.

[17] Gungor V. C, Bin Lu, Hancke G. P., "Opportunities and Challenges of Wireless Sensor Networks in Smart Grid," IEEE Transactions on Industrial Electronics, vol. 10, pp. 3557-3564, 2010.

[18] Shahid Bilal, Zubair Ahmed, Faroqi Adnan, Navid-ur-Rehman Rao M., "Implementation of Smart System Based on Smart Grid Smart Meterand Smart Appliances," International Conference on Smart Grid Systems (ICSGS) IPCSIT, Singaporen, 2012.

[19] M. S. Jaganmohan, K. Manikandan Easun Reyrolle Ltd. "Challenges in Smart Meter Design," in Conference of Power system Protection and Automation, New Delhi, India. 2010.

[20] "Getting smart about smart meters answer book for residential customers", POWER STREAM (vender company).

[21] Orlean Koehle. "The Latest in Bio-Hazard Technology", Printed by ARC Reproductions, Rohnert Park, CA 94928, Information Compiled Fall and Winter of 2010

[22] P. Michael Henderson, "56Kbps Data Transmission Across the PSTN," Document, Nov 18, 1998.

Int J Pow Elec \& Dri Syst Vol. 11, No. 1, Mar 2020 : 107 - 118 